\title{
Acknowledgments and Credits
}

\section{Acknowledgments}

This sixth issue of Tusaaji benefited greatly from the dedication and expertise of several collaborators. First and foremost, we are grateful to our guest editor, Prof. Şehnaz Tahir Gürçağlar, for contributing her expertise and hours of work to see this issue, on the topic "Traces", to completion.

We are grateful to all the contributors whose work is featured in this issue for considering Tusaaji and for granting permission to publish their work. For all images in the articles, the permissions were secured by the contributors.

We thank the publication Yanık Divvan, Dramatik Şiirler 2010-2016 (Kırmızı Kedi, Istanbul, 2016) for granting permission to reprint Enis Batur's poem "Korku", and Prof. Saliha Paker for allowing her translation of the poem to be published in Tusaaji.

Our thanks to our editorial and translation team, and to all the scholars and members of the editorial board who participated in the peer-review process. We are deeply grateful to Andrea Kosavic and her Digital Initiatives team at York University for their continuous support and assistance.

\section{Credits}

Junior Editorial Assistant: Alina Zdrazhko

Cover image: Artist: Bilge Friedlaender. Title: Square Mutation: Denying Gravity \#10 (1975, watercolor, pencil and telephone wire on paper, $56 \times 76 \mathrm{~cm}$ (art-work (C) Estate of Bilge Friedlaender; photograph by Hadiye Cangökçe provided by Vehbi Koç Foundation Contemporary Art Collection, Istanbul).

Translators:

Portuguese: Junia Claudia Santana de Mattos Zaidan

French: Anne Beinchet.

Spanish: Karelia Báez-Sánchez

Copyeditor: Martin Boyd, Diálogos Intercultural Services.

Funding for Tusaaji is partly provided by York University (Glendon) research funds. 